\title{
Improving the Industrialization of a New Product in an International Production Network: A Case Study from the Machinery Industry
}

\author{
Donatella Corti and Saransh Choudhury \\ Dept of Management, Economics and Industrial Engineering, \\ Politecnico di Milano P.zza Leonardo da Vinci, 32, 20133 Milano, Italy \\ donatella.corti@polimi.it, saransh.choudhury@imim.polimi.it
}

\begin{abstract}
The paper deals with cross-functional disciplines affecting product industrialization in companies organized around an international production network. Aim of the paper is the development of a framework to support a company along the industrialization process taking into consideration that more than one plant located globally could be affected by the introduction of a new product. The framework is based on the use of the general morphological analysis and can be used at both strategic and tactical level by managers in medium sized manufacturing enterprises. The framework is tailored to a case study company and then some operational guidelines are provided to develop the industrialization framework for other organizations.
\end{abstract}

Keywords: global operations, machinery, industrialization process, new product development.

\section{Introduction}

A new product generally takes a tangible form after market survey, concept validation in research laboratory, followed by development and testing. A number of activities need to be carried out at all stages of the product life-cycle to ensure that products are manufactured at desired locations, at targeted cost, on schedule, and with the features demanded by customers. Based on literature review and interaction with practitioners in industry, these activities were found to be interchangeably called commercialization, industrialization, localization or product launch (Swink and Song, 2007; Song and Montoya-Weiss, 1998). In absence of a common definition, in this paper industrialization is defined as all upstream activities aimed at designing the production process of new products at the desired manufacturing location (including offshore plants).

Globalization and the emergence of developing countries have meant that product development, manufacturing and marketing decisions happen in far-flung geographical locations (Abele et al., 2008). The process of industrialization becomes further challenging due to physical distance between manufacturing facilities and development centre, language barriers and cultural differences across locations. Companies 
would like to have a standard quality of products irrespective of the location where the new product is produced and to take advantage of cost savings associated with offshore manufacturing. The aim of this paper is the development of a framework that could structure the industrialization process of an Italian medium sized company producing capital goods and with an international production network. An attempt is done to generalize the empirical findings and some guidelines are provided to support companies in a similar context to develop their own industrialization process.

\section{$2 \quad$ Literature Review}

For a review on industrialization some contributions can be found in the literature dealing with supply chain management and New Product Development (NPD).

Cooper et al. (1997) developed a supply chain framework to increase the understanding of supply chain. They suggested that the SCM framework consists of three main elements: the structure of supply chain, the supply chain business processes, and supply chain management components. Lambert et al. (1998) extended this framework by providing options for managing the links across the supply chain. Spens and Bask (2002) after applying the framework by Lambert et al. (1998) to the Red Cross blood transfusion service, concluded that in its original form was too complex to map the supply chain, as too many levels and components had to be considered simultaneously. Consequently, they suggested that the framework could be further developed and simplified by concentrating on main processes and components. Pero et al. (2010) created a framework for NPD and supply chain. They carried out case study analysis at four companies to study the effect of product design features - modularity, variety and innovativeness on supply chain performance. They concluded that if a product is highly modular, high level of variety and innovativeness might be tolerated. If the product has an integral architecture and the product is highly innovative, it is necessary to sacrifice variety. Hicks et al. (2000) studied the unique supply chain management in low-volume engineer to order (ETO) product organizations. They concluded that the low volume ETO companies have limited influence over buyers.

Eppinger and Chitkara (2006) provided a framework for global product development and listed the key success factors that help companies overcome its challenges. Abele et al. (2008) presented their extensive study of global production dealing with areas of drivers for international manufacturing, selection criteria of sites, manufacturing network design, technology usage, ramp up suggestions, sourcing guidelines and alignment of R\&D. From the analysis of the existing frameworks, it can be drawn that:

- there are no frameworks specifically meant to aid the industrialization process of products in either bigger or smaller companies;

- most of the available frameworks deal with the broader issues of supply chain development and NPD, whilst limited attention is paid to industrialization.

To sum up, there are two types of research contributions: frameworks with strategic issues, but at very high level of abstraction and with little guidance for the 
practitioners; and research dealing with specific areas of industrialization, but without consideration of upstream and downstream processes. In absence of a unified framework supporting the industrialization process as a whole for international production network, first step towards the development of the proposed framework is the identification of activities to be included in the process of interest.

\subsection{The Activities and Processes Impacting Industrialization}

The industrialization of a product is a cross functional activity requiring inputs from different functional departments. Since a clear definition of industrialization is missing, the choice of activities which have been discussed here are based on literature review, interaction with practitioners and author's experience as a practitioner in industry. The list of selected activities and the available options follows.

- New product development process. It can be carried out using a stage gate process, a phased review method or without use of any formal NPD process. In a stage gate method, the NPD process is divided into many stages. Each stage requires execution of a specific set of activities by different members of the cross functional team (CFT). Each stage is followed by a gate, a meeting of the CFT and the management sponsors. During the gate meeting, the activities of the previous stage of the NPD process are reviewed. The financial projections and technical specification of the new product or service under development are reviewed. A decision is taken by the sponsors to allow the project to move to the next stage of the development process (Cooper, 1990, 2008). In the phased review method NPD is broken down into activities which are assigned to different functional departments. The responsibility of each functional department ends when semi completed work in progress is handed over to the internal customer within the organization. As a result, there is no commitment to the project from beginning to end by any one group.

- Team Structures. NPD as well as industrialization in organizations may be carried out using very different team structures and collaboration techniques. They may be classified as CFT, 'pseudo CFT' and department driven development. Team structure impacts the efficiency and effectiveness of industrialization and NPD process.

- Product design consideration. The design approach can broadly be classified as modular, platform and integrated (or customized). The product architecture has a profound impact on the industrialization of products.

- Knowledge management. Knowledge can be classified into two broad categories explicit and tacit knowledge (Nonaka and Takeuchi, 1995). Explicit knowledge can be relatively easily transferred, shared and explained (Killing, 1980). On the contrary, tacit knowledge is ingrained in action and is linked to concrete contexts.

- Make-or-buy decisions. For industrialization of new products, organizations have to take a decision to make products parts and assemblies in-house or to buy it from suppliers. The decision impacts the preservation of a company's core competences.

- Vendor Selection. The vendor selection for product industrialization refers to the distribution among existing or new vendors of the new business opportunities generated by the industrialization. 
- Supplier relationship. The relationship with suppliers affects the ease with which new products can be industrialized because of reliability and flexibility on the part of the suppliers. A first approach suggested by Kraljic (1983) prescribes supplier relationship based on strategic importance of the specific component and the complexity of the supply market. Based on the evaluation, a type of supplier relationship is chosen. In alternative, it is possible to start by evaluating the type of relationship and the attractiveness of the supplier (Olsen and Ellram, 1997). Based on the above evaluation, parts are assigned to suppliers.

\section{The Proposed Framework}

The development of the industrialization framework for the case study is done using general morphological analysis adapted to the field of interest. Fritz Zwicky pioneered the development of General morphological analysis (GMA) as a method for investigating the totality of relationships contained in multi-dimensional, nonquantifiable problem complexes (Zwicky, 1969) and was further used by Ritchey (1998) in several applications. The industrialization of products for a multinational company deals with different functions, geographies, cultures and knowledge bases, a qualitative GMA was considered an appropriate tool, even tough the GMA has been never used in this field. In particular, GMA was used to identify the activities of industrialization and then to list the corresponding methodologies. Then the total number of configurations possible by choice of one methodology for each activity was reduced by use of cross consistency assessment (CCA). The output of GMA is a set of possible configurations for industrialization of products. For sake of operational usefulness, the number of configurations has been further refined by introducing certain drivers that may reflect the product and corporate strategy of the company. A guideline for the extension of the use of the framework for other firms is also provided.

\section{The Case Study: CM S.p.A}

CM S.p.A is a medium sized Italian industrial machinery manufacturer employing approximately 1200 people around the world. The company has two development centers in Italy, each focusing on a specific family of products and four assembly facilities (two in Italy, one in South America and one in China). The development centers design machines and produce the first prototype. Most of the products are made according to an engineer to order (ETO) approach. The pace of innovation is slow to medium. The lead time for a customer order varies from five to eight months. For the product industrialization, the company has in place what can be defined as a stage gate method. During the stage gate meeting that takes place once a month, the senior and middle management reviews the product, but the project team members who carry out the actual work are not present. The project team was not structured as well as the responsibilities assignment. The platform design approach is used for new product design. The knowhow of the employees in development centers as well as in assembly is not codified. The knowledge in areas such as design, assembly, and 
testing of machines is passed on from one generation of employees to the other orally and by observation. This implies that the organization does not have structured manufacturing processes for assembly of prototypes at its facilities in Italy. Make-or-buy decisions are made without following a structured procedure by individuals in development and procurement functions at different stages of the product lifecycle. All assemblies are done in-house. The supplier selection is ad-hoc and varies across geographies: is driven by cost only in Italy, while in China quality is the most important factor. The relationship with all vendors is also managed in an ad-hoc fashion. The company signs annual rate contract with some important vendors, but a formal classification of products and management of relationship is not carried out. The current state represented by a lack of standardization can be attributed to the explosive growth without attention to standardized processes in the last two decades. The growth of CM S.p.A. was a result of a very important patent that transformed the industry. Main challenges for the industrialization process can be summarized as follows:

- $\quad$ variation in product quality at different manufacturing locations;

- asymmetrically dispersion of knowledge across locations;

- no proper product architecture for global sourcing and global industrialization;

- long lead times for NPD and industrialization.

\subsection{Framework Development for CM S.p.A}

The first step of the industrialization process was the creation of the industrialization Zwicky box (IZB) that lists all the activities that impact on industrialization (see Table 1). The first column in the IZB lists the industrialization activities and for each one, the corresponding methodologies are put in the right side of the table.

Table 1. - Zwicky industrialization box (IZB)

\begin{tabular}{|c|c|}
\hline Activity & Methodologies \\
\hline \multirow{3}{*}{ NPD process } & Stage Gate method \\
\hline & Phased Review method \\
\hline & No formal NPD method \\
\hline \multirow{3}{*}{ Team organization } & Cross functional team (CFT) \\
\hline & Pseudo CFT \\
\hline & Individual department driven development \\
\hline \multirow{3}{*}{$\begin{array}{l}\text { Product design } \\
\text { consideration }\end{array}$} & Integrated product Design \\
\hline & Platform product design \\
\hline & Modular product design \\
\hline \multirow{2}{*}{$\begin{array}{c}\text { Tacit knowledge } \\
\text { transfer }\end{array}$} & Codification and sharing of important processes \\
\hline & Intra company personnel transfer \\
\hline \multirow{4}{*}{$\begin{array}{l}\text { Make-or-buy deci- } \\
\text { sions }\end{array}$} & Strategy driven make-buy decision \\
\hline & Maximization of contribution margin \\
\hline & Process Technology driven \\
\hline & Integrated make-buy decision \\
\hline \multirow{3}{*}{ Vendor selection } & Data envelopment analysis (DEA) \\
\hline & Simple multi criteria rating technique (SMART) \\
\hline & Analytic Hierarchy Process (AHP) \\
\hline \multirow{2}{*}{$\begin{array}{c}\text { Supplier relation- } \\
\text { ships }\end{array}$} & Exploit, balance or Diversify (Kraljic Martix) \\
\hline & Relationship management (Olsen matrix) \\
\hline
\end{tabular}


With the above IZB, the total number of possible configurations is 1296 $(3 \times 3 \times 3 \times 2 \times 4 \times 3 \times 2)$. A configuration is defined as a set of choices including one methodology for each of the activity constituting industrialization as defined in the current research. The next step has been the cross consistency assessment (CCA) to reduce the number of industrialization configurations to get a manageable number. Using the CCA, pairs of activities are checked for logical, empirical or normative contradictions (Ritchey, 1998). Logical contradictions are those that are based on the nature of the concepts involved. Empirical contradictions are those relationships judged to be highly improbable or implausible on empirical grounds. Normative contradictions are relationships ruled out on e.g. ethical or political grounds. A detailed analysis of all the contradictions found for the CM case study does not find space in here, but after CCA the total number of configurations was reduced to 24 . Among the remaining, the number of configurations which do not reflect the company's product and corporate strategy were eliminated based on the drivers explained in the next section. For instance, a configuration containing Phased review method and pseudo CFT was eliminated as the organization's senior management has taken a strategic decision to develop the products using a stage gate method. The international nature of operations requires that the company's decision making should be based on objective data which can be audited and compared across locations. Thus the supplier relationship has to be based on the use of the Kraljic matrix (Kraljic, 1983). As a result of the GMA and the reduction of configurations guided by drivers, the final industrialization framework that is considered most suitable for CM S.p.A. is the one shown in Table 2.

Table 2. - Zwicky industrialization box (IZB) adapted to the CM case

\begin{tabular}{|c|c|c|c|c|c|c|}
\hline $\begin{array}{c}\text { NPD } \\
\text { process }\end{array}$ & Team & $\begin{array}{c}\text { Product } \\
\text { Design }\end{array}$ & $\begin{array}{c}\text { Knowledge } \\
\text { transfer }\end{array}$ & $\begin{array}{c}\text { Make-or- } \\
\text { buy deci- } \\
\text { sion }\end{array}$ & $\begin{array}{c}\text { Vendor } \\
\text { Selection }\end{array}$ & Supplier relationship \\
\hline $\begin{array}{c}\text { Stage Gate } \\
\text { method }\end{array}$ & CFT & $\begin{array}{c}\text { Modular } \\
\text { product }\end{array}$ & $\begin{array}{c}\text { Codification and } \\
\text { sharing of impor- } \\
\text { tant processes }\end{array}$ & $\begin{array}{c}\text { Strategy } \\
\text { driven make- } \\
\text { buy decision }\end{array}$ & SMART & $\begin{array}{c}\text { Exploit, balance or } \\
\text { Diversify (Kraljic } \\
\text { Matrix) }\end{array}$ \\
\hline $\begin{array}{c}\text { Stage Gate } \\
\text { method }\end{array}$ & CFT & $\begin{array}{c}\text { Modular } \\
\text { product }\end{array}$ & $\begin{array}{c}\text { Intra company } \\
\text { personnel transfer }\end{array}$ & $\begin{array}{c}\text { Strategy } \\
\text { driven make- } \\
\text { buy decision }\end{array}$ & SMART & $\begin{array}{c}\text { Exploit, balance or } \\
\text { Diversify (Kraljic } \\
\text { Matrix) }\end{array}$ \\
\hline
\end{tabular}

The suggestions provided in the research will require time and effort for implementation at CM S.p.A. However, the immediate impact that was observed in the company was a review of the product design strategy and the set up of a new industrial engineering department for industrialization of products. Also, the activities at each stage of the NPD process and the gates are being standardized using a RACI (Responsible, Accountable, Consult, Inform) matrix.

\section{Generalization of the Framework}

An attempt of generalization can be done in order to derive a procedure that could support a company along the industrialization process. Even though a single case 
study has been used, the literature review used for the framework development in CM has been wide enough to identify how some considerations can be extended to similar context. In particular, what follows is valid for medium sized companies operating in the B2B industry and offering complex products. Further empirical analysis should be carried out in order to better identify the impact of cultural elements on the framework, in particular for the "tacit knowledge transfer" activity. Nonetheless, since the level of the framework is quite aggregate, it is reasonable to think that the same set of methodologies can be generalized, whilst what depends on the local culture is how the methodology is implemented. A stepwise procedure has been identified:

- STEP 1: Start with the industrialization Zwicky box as in Table 1. More methodologies for each relevant activity could be added according to the needs.

- STEP 2: Carry out cross consistency assessment to reduce the number of configurations based on the three types of contradictions - logical, empirical and normative. Contradictions may vary across companies and thus must be carefully analyzed to reduce number of configurations.

- STEP 3: Choose or reject certain methodologies for industrialization activities based on drivers for industrialization. Drivers that may be considered during the choice of methodologies are summarized in Figure 1.

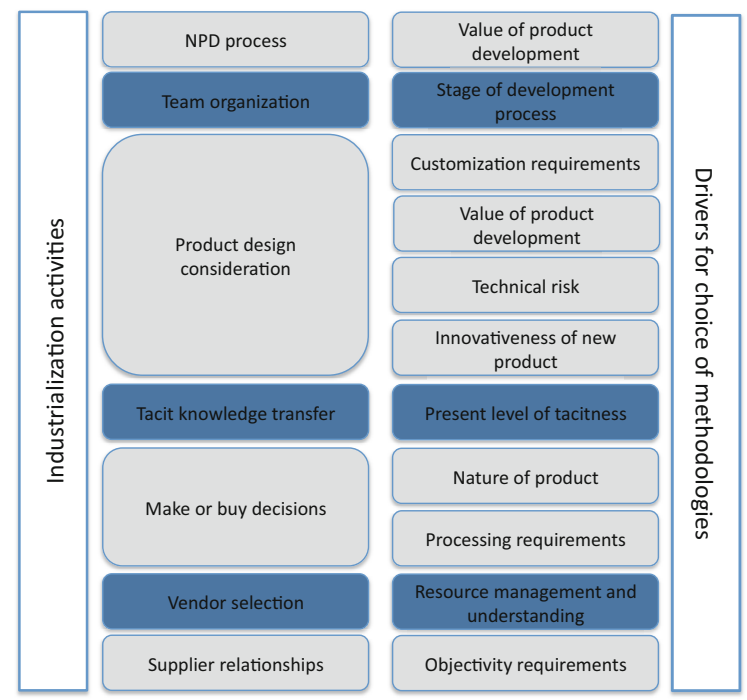

Fig. 1. - Industrialization activities and drivers for choice of methodologies

\section{Conclusion}

This research work provides a framework for industrialization of products across an international production network of an Italian medium sized machinery manufacturer and identifies a methodology for the framework development for similar companies. 
From a practical point of view, the framework proposal should guarantee the coherency of the different strategies across functions leading to an improvement of efficiency and effectiveness of the NPD and the industrialization process. From an academic point of view, the proposed methodology can act as a starting point for future research in this area. As a further development of this work, the preparation and implementation of the industrialization framework in more cases is advisable in order to validate the GMA and the drivers used in the current research.

\section{References}

1. Abele, E., Meyer, T., Näher, U., Strube, G., Sykes, R.: Global Production - A Handbook for Strategy and Implementation. Springer, Berlin (2008)

2. Cooper, R.: Jun.: Stage-gate systems: A new tool for managing new products. Business Horizons 33(3), 44-54 (1990)

3. Cooper, M.C., Lambert, D.M., Pagh, J.D.: Supply chain management: More than a new name for logistics. The International Journal of Logistics Management 8(1), 1-14 (1997)

4. Cooper, R.G.: May: Perspective: The Stage-Gate ( Idea-to-Launch Process Update, what's new, and Negev systems. Journal of Product Innovation Management 25(3), 213-232 (2008)

5. Eppinger, S.D., Chitkara, A.R.: The new practice of global product development. MIT Sloan Management Review 47(2), 532-550 (2006)

6. Hicks, C., McGovern, T., Earl, C.F.: Supply chain management: A strategic issue in engineer to order manufacturing. International Journal of Production Economics 65(2), 179-190 (2000)

7. Killing, P.: Technology acquisition: License agreement or joint venture. Columbia Journal of World Business, 38-46 (Fall 1980)

8. Kraljic, P.: Purchasing must become supply management. Harvard Business Review 61(5), 109-117 (1983)

9. Lambert, D.M., Cooper, M.C., Pagh, J.D.: Supply chain management: Implementation issues and research opportunities. The International Journal of Logistics Management 9(2), 1-20 (1998)

10. Nonaka, I., Takeuchi, H.: The Knowledge-Creating Company: How Japanese Companies Create the Dynamics of Innovation. Oxford University Press, New York (1995)

11. Olsen, R.F., Ellram, L.M.: A portfolio approach to supplier relationships. Industrial Marketing Management 26(2), 101-113 (1997)

12. Pero, M., Abdelkafi, N., Sianesi, A., Blecker, T.: A framework for the alignment of NPD and supply chains. Supply Chain Management: An International Journal 15(2), 115-128 (2010)

13. Ritchey, T.: Fritz Zwicky, Morphologie and Policy Analysis. In: 16th Euro. Conference on operational Analysis, Brussels (1998)

14. Song, X.M., Montoya-Weiss, M.M.: Critical development activities for really new versus incremental products. Journal of Product Innovation Management 15(2), 124-135 (1998)

15. Spens, K.M., Bask, A.H.: Developing a framework for supply chain management. The International Journal of Logistics Management 13(1), 73-88 (2002)

16. Swink, M., Song, M.: Effects of marketing-manufacturing integration on NPD time and competitive advantage. Journal of Operations Management 25(1), 203-217 (2007)

17. Zwicky, F.: Discovery, Invention, Research Through the Morphological Approach, 1st American edn. Macmillan (1969) 